\title{
Optimization of Planar Antenna Arrays Using the Firefly Algorithm
}

\author{
Eduardo Yoshimoto (iD) and Marcos V. T. Heckler (D) \\ Laboratório de Eletromagnetismo, Micro-Ondas e Antenas - LEMA \\ Universidade Federal do Pampa (UNIPAMPA) - Campus Alegrete, Alegrete - RS, Brazil \\ yoshi.edu@gmail.com; marcos.heckler@unipampa.edu.br
}

\begin{abstract}
This paper describes the application of the Firefly Algorithm for the optimization of linear and planar antenna arrays. In order to demonstrate the potential of this technique, three applications are reported. The first one is the synthesis of a radiation pattern with isoflux distribution with a non-uniformly spaced linear array composed of isotropic antennas. The second application is the optimization of a non-uniformly spaced planar array composed of isotropic radiators installed on an 8-U nanosatellite. Finally, the optimization of a $3 \times 3$ planar antenna array for beam steering with simultaneous side lobe level control is described, whereby the beamforming coefficients were allowed to assume only discrete values. In the three cases considered, good agreement between the desired (mask) and the optimized patterns has been obtained.
\end{abstract}

Index Terms-Beamforming, Firefly Algorithm, microstrip antennas, microstrip arrays, nanosatellites, non-uniformly spaced antenna arrays.

\section{INTRODUCTION}

The beamforming is an important topic in wireless communications, since realistic antennas provide spatial filtering, i.e. an antenna receives/radiates different power levels depending on the direction of signal incidence/radiation [1]. In order to achieve beamforming, antenna arrays are applied normally in linear, planar, circular or spherical configurations. Thus, according to [1], in addition to the geometric arrangement, there are four additional design parameters: the distance between the array elements, the amplitude and the phase of the excitation coefficients, and the elemental radiation pattern. Due to the fact that the design parameters allow infinite combinations, sophisticated (or complex) patterns can only be synthesized by using a proper optimization approach.

In order to deal with this issue, many optimization methods can be used to find the best set of design parameters that generates a desired radiation pattern, also called mask. In most cases, heuristic methods are appropriate, such as the Genetic Algorithm (GA) [2]-[7], the Particle Swarm Optimization (PSO) [8]-[12], the Ant Colony Optimization (ACO) [13]-[17], and the Cat Swarm Optimization (CSO) [18] to cite only a few. There are also optimization methods that are based on the Calculation Theory, such as the Sequential Quadratic Programming (SQP) and the Gradient Method (GM) [19], [20]. When optimization methods are applied in beamforming, they try to find optimal values for the design parameters in such a way as to minimize the deviation of the synthesized 
radiation pattern from the desired pattern (mask).

In [21], two annular ring antenna arrays of isotropic elements were modeled in order to produce an isoflux radiation pattern for satellites operating in Geostationary Orbit (GEO) and Medium-Earth Orbit (MEO). Differential evolution was used for beamshaping and, at the same time, to minimize the sidelobe level (SLL) [22]. The optimization yielded both arrays with diameter equal to $4 \lambda$, which allowed low deviation from the desired main beam shape and SLL of $-26.97 \mathrm{~dB}$ and $-23.8 \mathrm{~dB}$ for the satellites operating in GEO and MEO, respectively.

In [23], an annular ring antenna array was also designed to produce an isoflux radiation pattern. The antenna array operates in X-band with circular polarization obtained by using sequential rotation of the elements and has been integrated onto one of the faces of a 1-U nanosatellite. The magnitudes and phases of the excitation coefficients and the radii of the two concentric rings were optimized using GA. The synthesized pattern showed deviation from the mask that has been attributed to the absence of mutual coupling in the model used for the synthesis.

Another heuristic applicable to pattern synthesis is the Firefly Algorithm (FA) optimization method, which was introduced by [24] in 2009. This method is based on the behavior of fireflies in searching a partner for mating, attracting preys or as a mechanism of protection against predators. The firefly that presents the best response to a particular goal generates bioluminescence with larger intensity, which attracts the rest of the colony. The attraction is weighted according to the distance between the fireflies and depends on the decaying nature of light propagation. In addition, in order to allow the fireflies to explore fully the search space, randomness must be included in the formulation. The efficiency of the method is demonstrated by [24], whereby optimizations of multi-dimensional mathematical functions and multiple optimal values have been demonstrated. The FA exhibited better performance in comparison to GA and PSO in $90 \%$ of the analyzed cases. Other applications of the FA have been reported in [25]-[29].

Due to these advantages, this paper describes the application of FA for beamforming scenarios typical for space applications. The next section presents the mathematical background for the FA implementation. With this formulation, three different applications of the proposed technique are presented: the synthesis of a radiation pattern with isoflux distribution with a non-uniformly spaced linear array of isotropic antennas is described in section III, the optimization of a non-uniformly spaced planar array of isotropic radiators installed on an 8-U nanosatellite is presented in section IV, and the modelling of a $3 \times 3$ planar antenna array for beam steering with simultaneous sidelobe level control is discussed in section V. In this last case, the beamforming coefficients were allowed to assume only discrete values.

\section{MATHEMATICAL BACKGROUND FOR THE FA IMPLEMENTATION}

Given the good performance of the FA in solving multidimensional problems, the equation presented by [24] is briefly described below, where the update of the position of the $i$-th non-optimal 
firefly towards the best located $j$-th firefly, i.e. the firefly who is supposed to be the closest to the optimum solution, is given by

$$
x_{i}^{t+1}=x_{i}^{t}+\beta_{0} e^{-\gamma r_{i j}^{2}}\left(x_{j}^{t}-x_{i}^{t}\right)+\alpha \varepsilon_{i}
$$

where $t$ represents the iteration, $\beta_{0}$ is the attractiveness between the fireflies, which can be in the range $[0,1], \gamma$ is the light absorption coefficient, which can be in the range [0.01, 100], $r_{i j}$ is the line-of-sight distance between the fireflies, $e^{-\gamma r_{i j}^{2}}$ is the decaying rate due to the light propagation, $\alpha$ is the randomness applied to the $i$-th firefly in the range $[0,1]$ and $\varepsilon_{i}$ is a uniformly distributed random scalar value between -1 and 1 . The parameters $\beta_{0}$ and $\gamma$ can be used to control the fireflies searching capability. For instance, if large values (in the respective allowed ranges) are set to $\beta_{0}$ and $\gamma$, than the fireflies tend to focus on local search. On the other hand, the fireflies can be driven to perform global search by attributing a large value (in the allowed range) to the parameter $\alpha$.

The term $r_{i j}$ is calculated by

$$
r_{i j}=\sqrt{\sum_{k=1}^{d}\left(x_{i, k}^{t}-x_{j, k}^{t}\right)^{2}},
$$

where $d$ is the amount of variables to be optimized. The dynamics described by (1) can be summarized in Fig. 1.

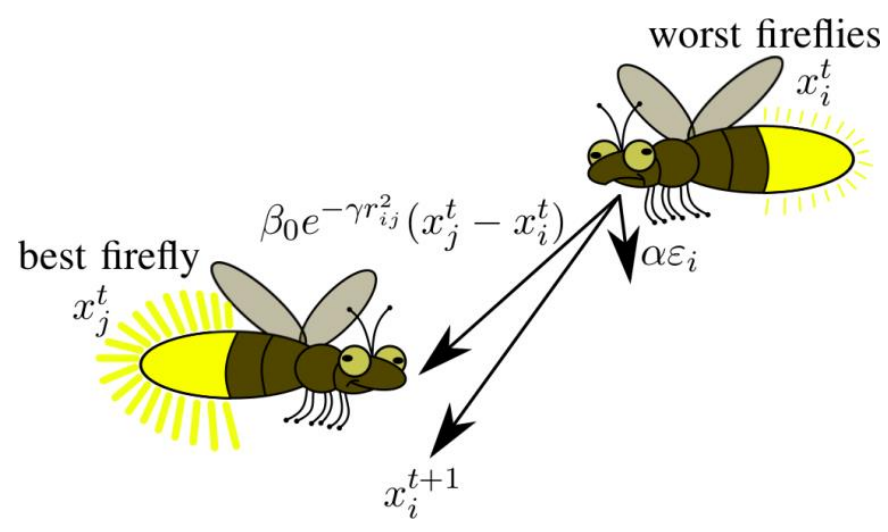

Fig.1. Basic mechanism of the FA.

The function to be optimized (minimized) is the error function, which, in this work, has been defined as

$$
\text { error }=\sum_{\phi=0^{\circ}}^{360^{\circ}} \sum_{\theta=0^{\circ}}^{90^{\circ}}\left|\vec{E}_{\text {mask }}(\theta, \phi)-\vec{E}(\theta, \phi)\right|,
$$

where $\vec{E}_{\text {mask }}$ is the electric field matrix referring to the desired mask and $\vec{E}$ corresponds to the 
synthesized electric field pattern, obtained according to Fig. 2 and mathematically by

$$
\vec{E}(\theta, \phi)=A F_{x_{\theta}}(\theta, \phi) A F_{y_{\theta}}(\theta, \phi) \hat{\theta}+A F_{x_{\phi}}(\theta, \phi) A F_{y_{\phi}}(\theta, \phi) \hat{\phi},
$$

with

$$
\begin{aligned}
& A F_{x_{\theta}}(\theta, \phi)=\sum_{m=1}^{N_{x}} a_{m n} E_{\theta_{m n}} e^{j\left(k_{0} x_{m} \sin \theta \cos \phi+\varphi_{m n}\right)}, \forall n=\left[1,2, \ldots, N_{y}\right], \\
& A F_{x_{\phi}}(\theta, \phi)=\sum_{m=1}^{N_{x}} a_{m n} E_{\phi_{m n}} e^{j\left(k_{0} x_{m} \sin \theta \cos \phi+\varphi_{m n}\right)}, \forall n=\left[1,2, \ldots, N_{y}\right], \\
& A F_{y_{\theta}}(\theta, \phi)=\sum_{n=1}^{N_{y}} a_{m n} E_{\theta_{m n}} e^{j\left(k_{0} y_{m} \sin \theta \sin \phi+\varphi_{m n}\right)}, \forall m=\left[1,2, \ldots, N_{x}\right], \\
& A F_{y_{\phi}}(\theta, \phi)=\sum_{n=1}^{N_{y}} a_{m n} E_{\phi_{m n}} e^{j\left(k_{0} y_{m} \sin \theta \sin \phi+\varphi_{m n}\right)}, \forall m=\left[1,2, \ldots, N_{x}\right],
\end{aligned}
$$

where $N_{x}$ and $N_{y}$ correspond to the number of elements along the $x$ and $y$ directions, respectively, $a_{m n}$ and $\varphi_{m n}$ are the amplitudes and phases of the excitation coefficients that should weight the field components $E_{\theta m n}$ and $E_{\phi m n}$ radiated by the $m n$-th array element, $k_{0}$ is the propagation constant in free space, and $x_{m}$ and $y_{n}$ are the coordinates of the $m n$-th array element.

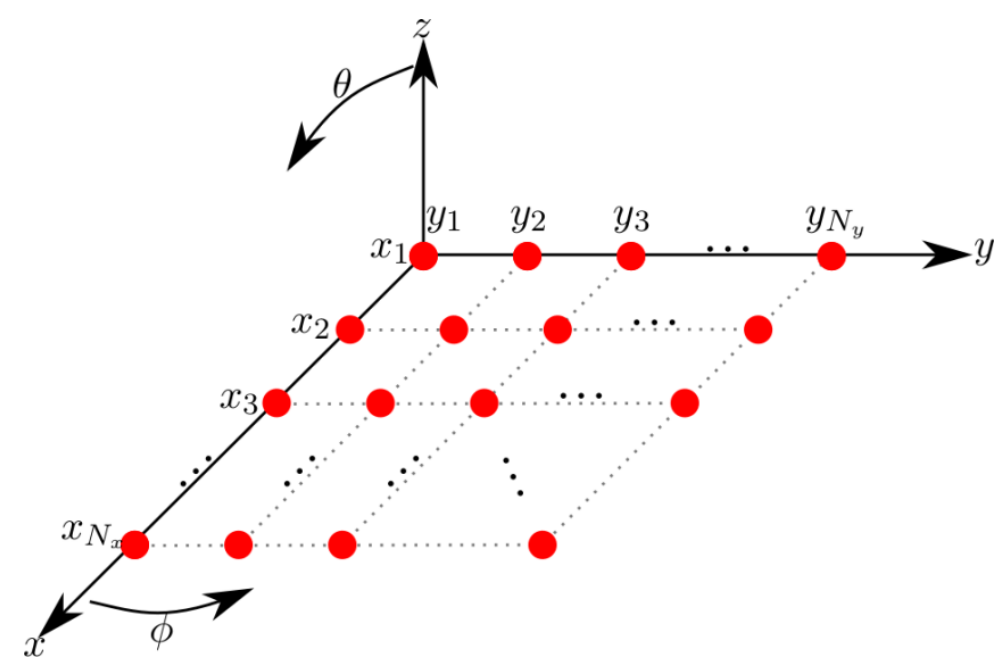

Fig.2. General geometry of a planar antenna array.

According to [26], for minimization problems, the brightness of each firefly is inversely proportional to the value of the error function, whereas for maximization problems, the brightness is directly proportional. For the present case, the FA has been implemented in a computer code in MATLAB following the flowchart shown in Fig. 3. 


\section{FA APPLICATION FOR NON-UNIFORMLY SPACED LINEAR ANTENNA ARRAY COMPOSED OF ISOTROPIC ELEMENTS}

The first proposed application for the FA considers a linear antenna array with 12 isotropic elements. The elements are arranged along the $x$ axis according to Fig. 4. The positions of the elements have been adjusted to the dimensions of an 8-U nanosatellite, which is shown in Fig. 5 flying over the Earth. The cubic structure, as well as the open flaps have edge sides of $20 \mathrm{~cm}$. The radiation pattern to be synthesized should follow an isoflux distribution, which is plotted as a black dotted curve in Fig. 6, so as to allow illuminating the Earth surface with constant power distribution. The main pattern constraints are shown in Fig. 5, with SLL $\leq-15 \mathrm{~dB}$ below the maximum of the radiation pattern.

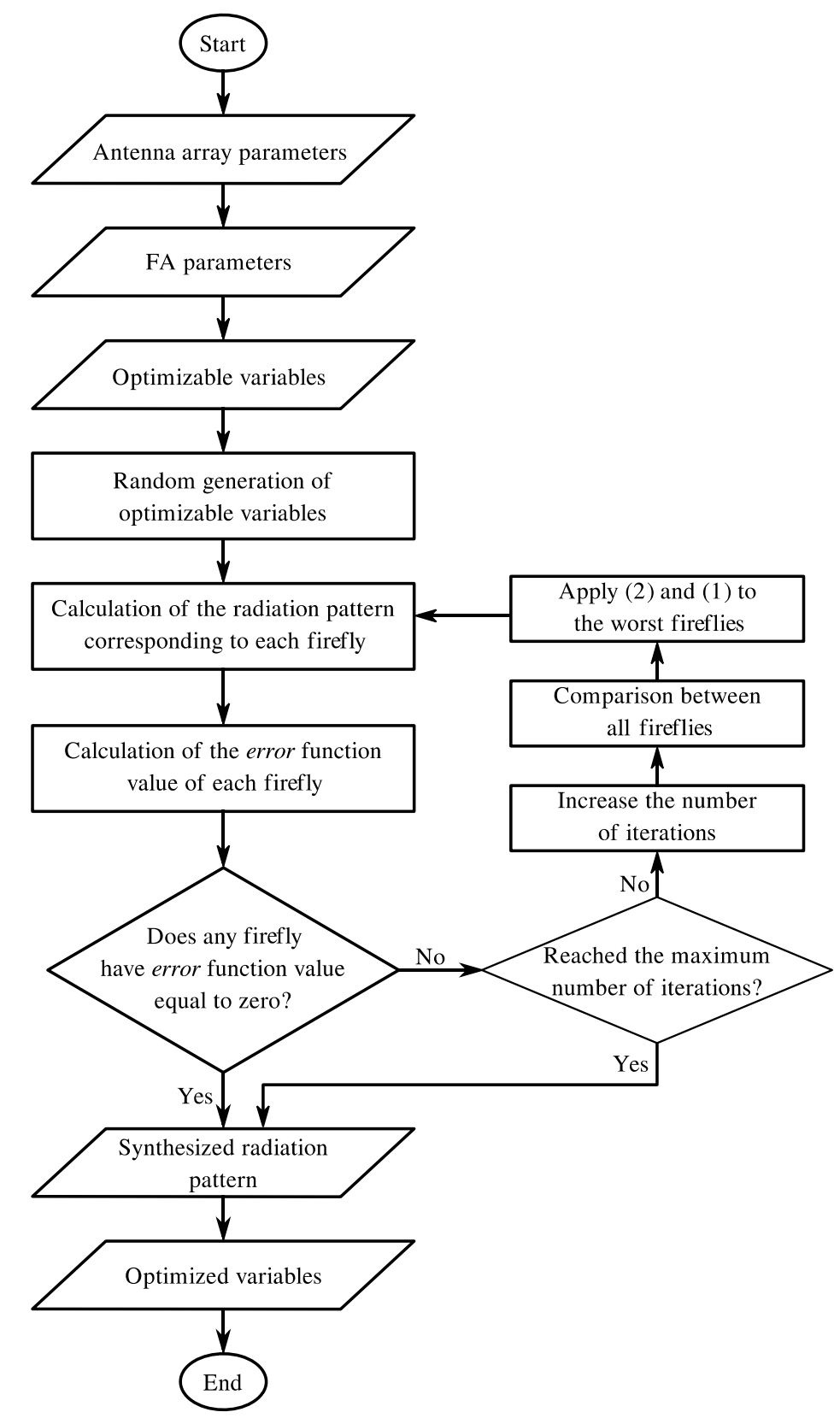

Fig.3. Flowchart of the computer code based on the FA. 


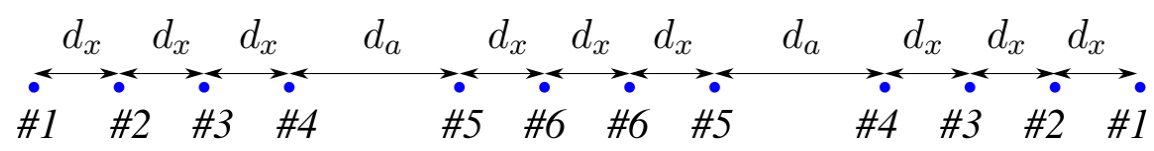

Fig.4. Positions of the elements on the linear antenna array along the $x$ axis (design frequency equal to $2.26 \mathrm{GHz}, d_{x}=0.3 \lambda_{0}$ and $\left.d_{a}=0.6 \lambda_{0}\right)$.

To start the FA optimization, 15 fireflies were randomly allocated in the search space. The parameters $\beta_{0}, \alpha$ and $\gamma$ were varied during the optimization process as given in Table I.

The resulting excitation coefficients are listed in Table II and the optimized radiation pattern is shown in Fig. 6. It is notorious that the synthesized radiation pattern satisfied the mask with irrelevant deviations around $\theta= \pm 45^{\circ}$. The regions without mask tracing are not considered in the calculation of (3). The value of the error function at the beginning of the optimization was 7.32 and, after 1000 iterations, the optimization was terminated with error $=0.18$, yielding a reduction to $2.46 \%$ of the initial value.

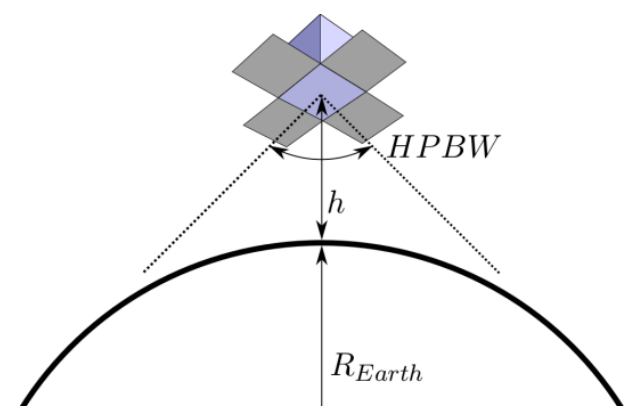

Fig.5. Typical scenario of a nanosatellite orbiting the Earth $\left(h=625 \mathrm{~km}, R_{\text {Earth }} \approx 6370 \mathrm{~km}\right.$ and $\left.H P B W=85^{\circ}\right)[30]$.

TABLE I. FA PARAMETERS FOR THE OPTIMIZATION OF THE LINEAR ANTENNA ARRAY.

\begin{tabular}{ccccc}
\hline Iterations & $\mathbf{1 - 2 5 0}$ & $\mathbf{2 5 1 - 5 0 0}$ & $\mathbf{5 0 1 - 7 5 0}$ & $\mathbf{7 5 1 - 1 0 0 0}$ \\
\hline Attractiveness $\left(\beta_{0}\right)$ & 0.5 & 0.7 & 0.9 & 1.0 \\
Randomness $(\alpha)$ & 0.100 & 0.050 & 0.010 & 0.001 \\
Light absorption coefficient $(\gamma)$ & 5.0 & 3.0 & 1.0 & 0.1 \\
\hline
\end{tabular}

TABLE II. EXCITATION COEFFICIENTS OBTAINED WITH FA FOR THE LINEAR ANTENNA ARRAY.

\begin{tabular}{ccc}
\hline Element & Magnitude $\left(a_{n x}\right)$ & Phase $\left(\varphi_{n x}\right)$ \\
\hline$\# \mathbf{1}$ & 0.19961 & $229.47^{\circ}$ \\
$\# \mathbf{2}$ & 0.55074 & $329.08^{\circ}$ \\
$\# 3$ & 0.88687 & $244.16^{\circ}$ \\
$\# 4$ & 0.55328 & $164.88^{\circ}$ \\
$\# \mathbf{5}$ & 0.12639 & $326.88^{\circ}$ \\
$\# \mathbf{6}$ & 1.00000 & $83.00^{\circ}$ \\
\hline
\end{tabular}




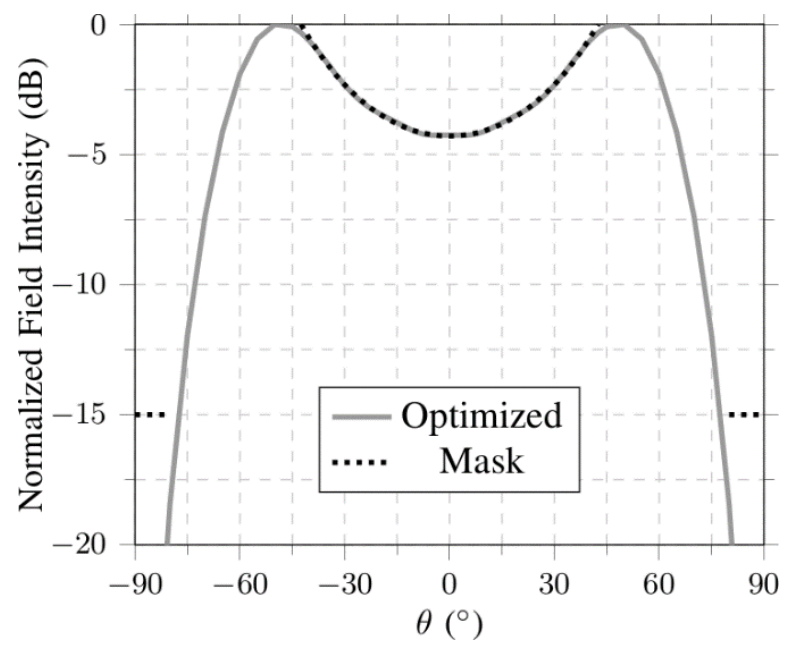

Fig.6. Desired and synthesized isoflux radiation pattern for the scenario shown in Fig. 5.

\section{FA APPLICATION FOR A PLANAR ANTENNA ARRAY OF ISOTROPIC ELEMENTS INSTALLED ONTO AN 8-U NANOSATELLITE}

For the scenario depicted in Fig. 5, the antenna should present a nearly rotation symmetric pattern following the contour defined in Fig. 6 for any $\phi$. This results in the two-dimensional mask for the upper hemisphere of the array $\left(0^{\circ} \leq \phi \leq 360^{\circ}\right.$ and $\left.0^{\circ} \leq \theta \leq 90^{\circ}\right)$ as shown in Fig. 7. In order to fulfill such a mask, a planar antenna array is needed. In a first scenario, the antennas could be placed onto the open flaps, and this is the case considered in this section. A second scenario would be to consider the antennas to be integrated onto the bottom surface of the 8-U cubic structure, which is the case to be analyzed in the next section.

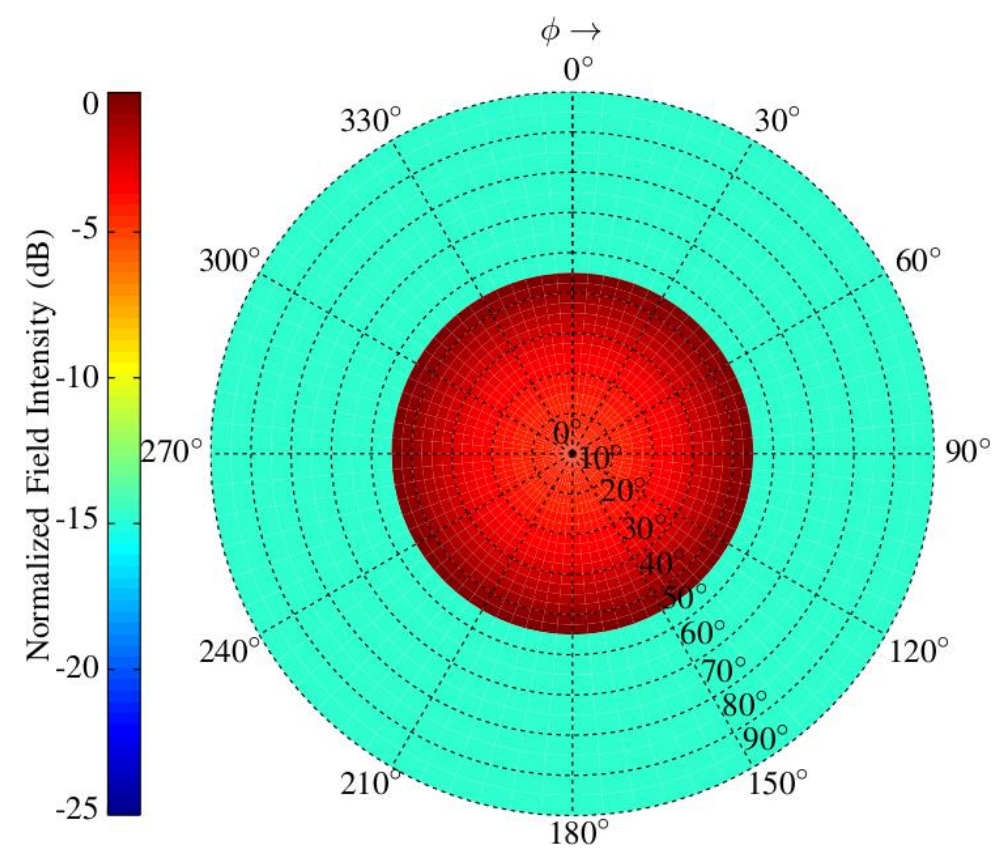

Fig.7. Isoflux radiation pattern for the characteristics shown in Fig. 5. The angular scale corresponds to the $\phi$ coordinate of the spherical coordinate system and the radial scale to the $\theta$ coordinate. The color scale indicates the desired electric field intensity.

The antenna array topology considered in this case is shown in Fig. 8. The nanosatellite structure itself and the design frequency $(2.26 \mathrm{GHz})$ yield an edge-to-edge distance between subarrays equal to Brazilian Microwave and Optoelectronics Society-SBMO received 30 July 2018; for review 2 Aug 2018; accepted 12 Dec 2018 
$280 \mathrm{~mm}$, or $2.11 \lambda_{0}$. In this way, according to [1], this geometry allows the appearance of grating lobes, which can be seen in Fig. 9 when all the elements are excited with uniform amplitude $\left(a_{m n}=1\right)$ and with the same phases $\left(\varphi_{m n}=0^{\circ}\right)$.

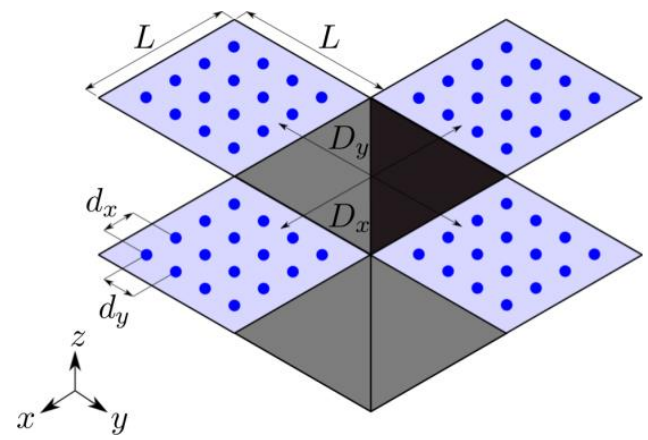

Fig.8. Non-uniformly spaced planar antenna array composed of 4 subarrays of $4 \times 4$ isotropic elements $\left(d_{x}=d_{y}=40 \mathrm{~mm}=0.3\right.$ $\lambda_{0}, D_{x}=D_{y}=280 \mathrm{~mm}=2.11 \lambda_{0}$ and $\left.L=200 \mathrm{~mm}=1.51 \lambda_{0}\right)$.

In Fig. 9, the angular aperture between the grating lobes is close to the angular aperture required for the isoflux distribution (Fig. 7). Thus, the FA was applied to the synthesis of an isoflux radiation pattern with SLL $\leq-15 \mathrm{~dB}$. For this case, the FA has been started with 10 fireflies with random values for excitation coefficients (magnitude and phase), whilst attractiveness, randomness and light absorption coefficients are varied according to Table III during the FA run.

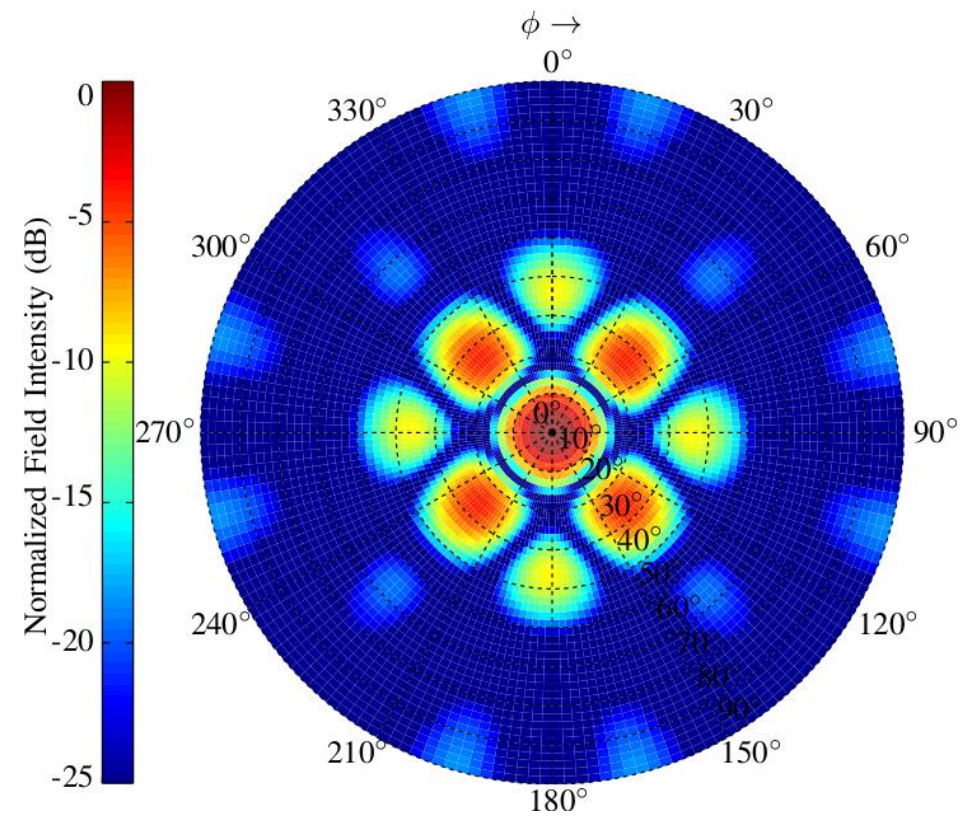

Fig.9. Radiation pattern produced by the antenna array of Fig. 8 for broadside radiation without SLL control. 
TABLE III. FA PARAMETERS FOR THE OPTIMIZATION OF THE PLANAR ANTENNA ARRAY.

\begin{tabular}{ccc}
\hline Iterations & $\mathbf{1 - 2 5 0}$ & $\mathbf{7 5 1 - 1 0 0 0}$ \\
\hline Attractiveness $\left(\beta_{0}\right)$ & 0.60 & 0.95 \\
Randomness $(\alpha)$ & 0.200 & 0.005 \\
Light absorption coefficient $(\gamma)$ & 2 & 1 \\
\hline
\end{tabular}

The synthesized isoflux radiation pattern can be seen in Figs. 10 and 11 as 3D polar plot with color scale and 2D rectangular plot for $\phi=90^{\circ}$, respectively. The shape of the synthesized isoflux radiation pattern was obtained successfully with deviations from the mask only in small regions of the main lobe. The value of the error function at the beginning of the optimization was 619.9 and could be reduced to 47.5 ( $7.66 \%$ of its initial value). These results confirm the good convergence behavior of FA in the optimization of multidimensional problems (128 variables in the present case).

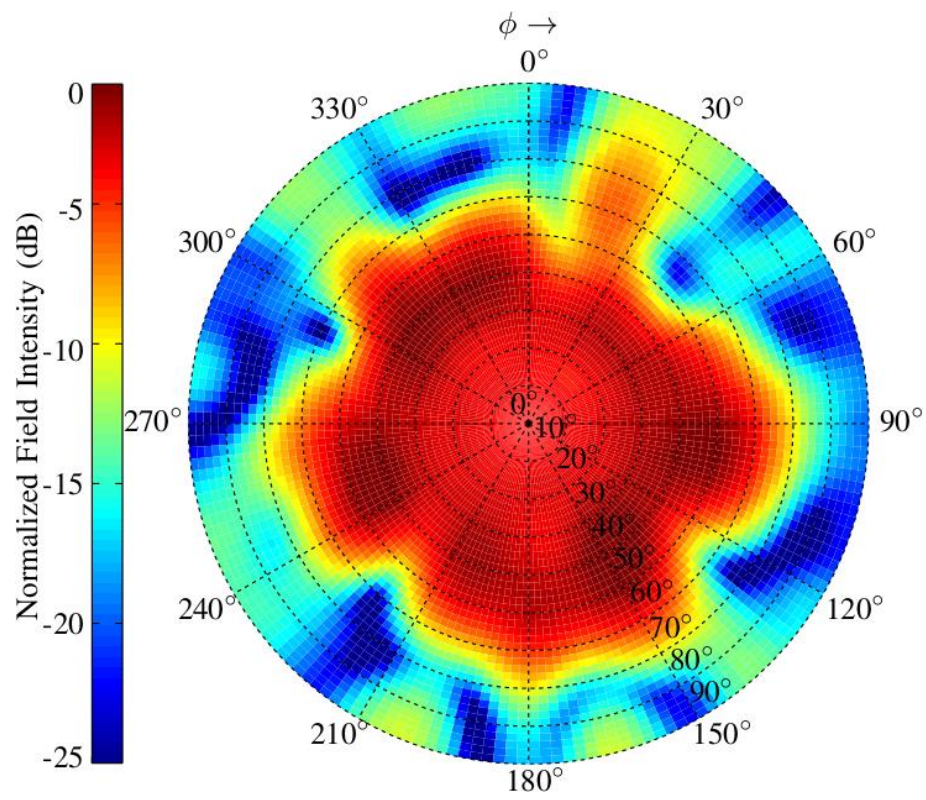

Fig.10. Isoflux radiation pattern produced by the antenna array of Fig. 8 with the excitation coefficients found by the FA optimization method.

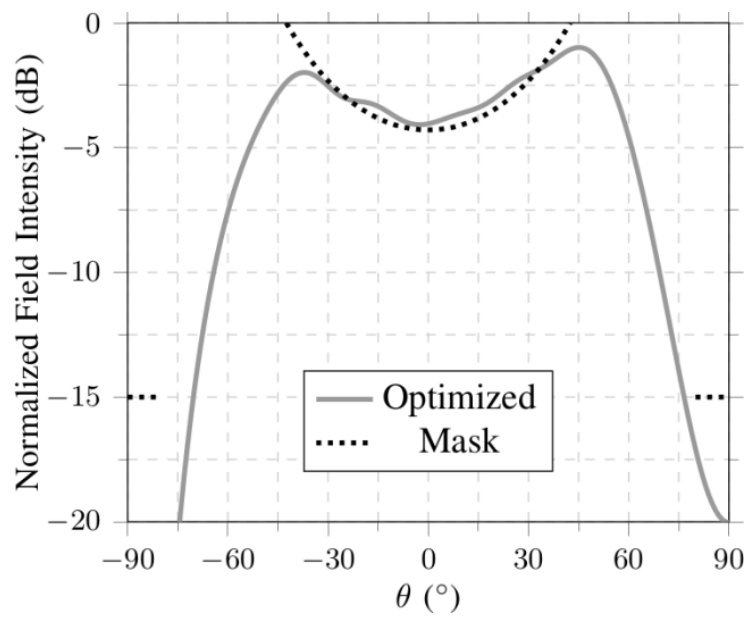

Fig.11. Radiation pattern for the $\phi=90^{\circ}$ plane of Fig. 10 . 


\section{FA APPLICATION FOR A REALISTIC PLANAR ANTENNA ARRAY WITH DISCRETE BEAMFORMING COEFFICIENTS}

In this case, a $3 \times 3$ planar array composed of realistic patch antennas with right-handed circular polarization (RHCP) and dimensions compatible with the bottom face of an 8-U CubeSat (200 mm of edge size) was considered. The geometry of the array element is based on the antenna designed in [31] and is detailed in Fig. 12. The geometry of the antenna array is shown in Fig. 13.

This array should be able to steer the main beam $45^{\circ}$ off from boresight and with SLL $\leq-20 \mathrm{~dB}$. For such an array, the worst case is normally achieved when beamsteering is done to $\phi_{\max }=\theta_{\max }=45^{\circ}$, whereby large sidelobes tend to appear. Since the array geometry is implemented now in microstrip technology, mutual coupling must be considered. This has been achieved by modelling the array in ANSYS HFSS and by extracting the embedded pattern of each element.

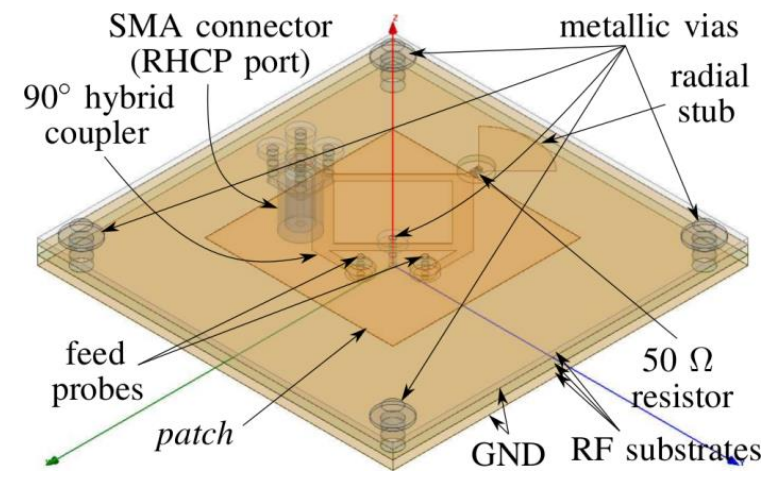

Fig.12. Right-handed circularly polarized patch antena.

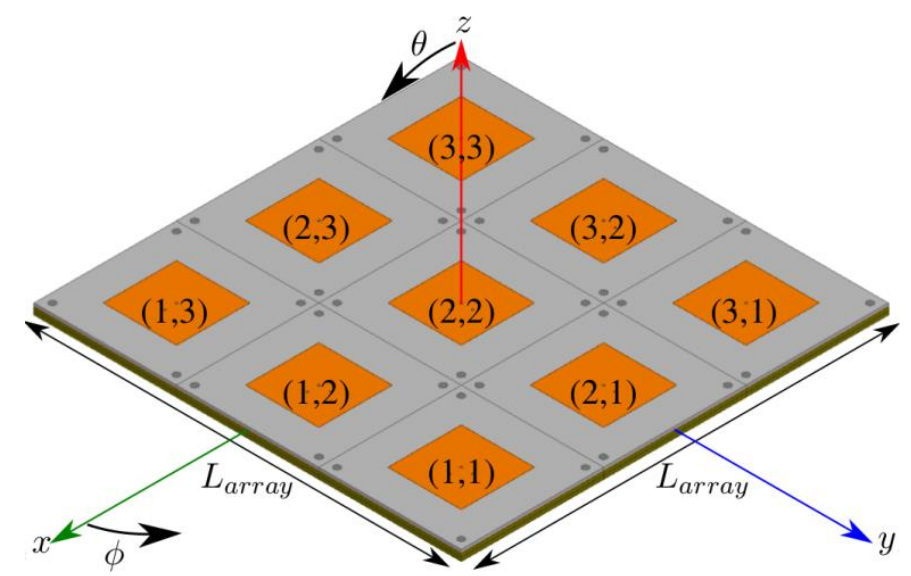

Fig.13. Right-handed circularly polarized $3 \times 3$ planar microstrip array $\left(L_{\text {array }}=199.5 \mathrm{~mm}\right.$, the distance of the center-to-center of elements is equal to $66.5 \mathrm{~mm}$ ). The figures between parenthesis stand for the identification of the $m n$-th array element.

The FA has been configured to work with 50 fireflies that have been randomly placed in the search space. The other parameters are listed in Table IV. In addition, the algorithm was configured to perform the optimization only for a discrete set of the excitation coefficients with 4-bit representation for both magnitude and phase. Thus, the magnitude can assume values between $0-15 \mathrm{~dB}$, with steps of $1 \mathrm{~dB}$, and the phase can range from $0^{\circ}$ to $337.5^{\circ}$, with steps of $22.5^{\circ}$. 
TABLE IV.FA PARAMETERS FOR THE OPTIMIZATION OF THE $3 \times 3$ PLANAR MICROSTRIP ARRAY.

\begin{tabular}{cccc}
\hline Iterations & $\mathbf{1 - 2 5 0}$ & $\mathbf{2 5 1 - 5 0 0}$ & $\mathbf{5 0 1 - 7 5 0}$ \\
\hline Attractiveness $\left(\beta_{0}\right)$ & 0.5 & 0.7 & 1.0 \\
Randomness $(\alpha)$ & 0.20 & 0.05 & 0.01 \\
Light absorption coefficient $(\gamma)$ & 10.0 & 5.0 & 0.1 \\
\hline
\end{tabular}

To demonstrate the technique in a realistic scenario, the FA has been applied to determine the beamforming coefficients to steer the main beam to the following directions (SLL $\leq-20 \mathrm{~dB}$ ): $\theta_{\max }=0^{\circ}$ and $\phi_{\max }=0^{\circ}, \theta_{\max }=15^{\circ}$ and $\phi_{\max }=45^{\circ}, \theta_{\max }=30^{\circ}$ and $\phi_{\max }=45^{\circ}$, and $\theta_{\max }=45^{\circ}$ and $\phi_{\max }=45^{\circ}$. The discrete excitation coefficients found by the FA are listed in Tables V-VIII. These coefficients produce the radiation patterns shown in Figs. 14-17, which have been calculated with ANSYS HFSS. The gains in the desired directions and the achieved SLL are summarized in Table IX.

TABLE V. EXCITATION COEFFICIENTS OPTIMIZED TO POINT THE MAIN BEAM TO $\theta_{\max }=0^{\circ}$ AND $\phi_{\max }=0^{\circ}$ WITH SLL $\leq-20 \mathrm{~dB}$. MAGNITUDES ARE GIVEN IN dB.

\begin{tabular}{|c|c|c|c|c|}
\hline & \multicolumn{3}{|c|}{$n$} \\
\hline & & 1 & 2 & 3 \\
\hline \multirow{3}{*}{$m$} & 1 & $3 \angle 0^{\circ}$ & $6 \angle 0^{\circ}$ & $4 \angle 0^{\circ}$ \\
\hline & 2 & $7 \angle 0^{\circ}$ & $10 \angle 0^{\circ}$ & $7 \angle 0^{\circ}$ \\
\hline & 3 & $4 \angle 0^{\circ}$ & $6 \angle 0^{\circ}$ & $3 \angle 0^{\circ}$ \\
\hline
\end{tabular}

TABLE VI. EXCITATION COEFFICIENTS OPTIMIZED TO POINT THE MAIN BEAM TO $\theta_{\max }=15^{\circ}$ AND $\phi_{\max }=45^{\circ}$ wiTH SLL $\leq-20 \mathrm{~dB}$. MAGNITUDES ARE GIVEN IN dB.

\begin{tabular}{|c|c|c|c|c|}
\hline & \multicolumn{3}{|c|}{$n$} \\
\hline & & 1 & 2 & 3 \\
\hline \multirow{3}{*}{$m$} & 1 & $3 \angle 0^{\circ}$ & $6 \angle 22.5^{\circ}$ & $4 \angle 45^{\circ}$ \\
\hline & 2 & $7 \angle 22.5^{\circ}$ & $10 \angle 45^{\circ}$ & $7 \angle 67.5^{\circ}$ \\
\hline & 3 & $4 \angle 45^{\circ}$ & $6 \angle 67.5^{\circ}$ & $3 \angle 90^{\circ}$ \\
\hline
\end{tabular}

TABLE VII. EXCITATION COEFFICIENTS OPTIMIZED TO POINT THE MAIN BEAM TO $\theta_{\max }=30^{\circ}$ AND $\phi_{\max }=45^{\circ}$ wiTH SLL $\leq-20 \mathrm{~dB}$. MAGNITUDES ARE GIVEN IN dB.

\begin{tabular}{|c|c|c|c|c|}
\hline & \multicolumn{3}{|c|}{$n$} \\
\hline & & 1 & 2 & 3 \\
\hline \multirow{3}{*}{$m$} & 1 & $3 \angle 0^{\circ}$ & $6 \angle 67.5^{\circ}$ & $4 \angle 135^{\circ}$ \\
\hline & 2 & $7 \angle 67.5^{\circ}$ & $10 \angle 135^{\circ}$ & $7 \angle 202.5^{\circ}$ \\
\hline & 3 & $4 \angle 135^{\circ}$ & $6 \angle 202.5^{\circ}$ & $3 \angle 0^{\circ}$ \\
\hline
\end{tabular}

TABLE VIII. EXCITATION COEFFICIENTS OPTIMIZED TO POINT THE MAIN BEAM TO $\theta_{\max }=45^{\circ}$ AND $\phi_{\max }=45^{\circ}$ WITH SLL $\leq-20 \mathrm{~dB}$. Magnitudes ARE GIVEN IN dB.

\begin{tabular}{|c|c|c|c|c|}
\hline & \multicolumn{3}{|c|}{$n$} \\
\hline & & 1 & 2 & 3 \\
\hline \multirow{3}{*}{$m$} & 1 & $3 \angle 0^{\circ}$ & $6 \angle 90^{\circ}$ & $4 \angle 180^{\circ}$ \\
\hline & 2 & $7 \angle 90^{\circ}$ & $10 \angle 180^{\circ}$ & $7 \angle 270^{\circ}$ \\
\hline & 3 & $4 \angle 180^{\circ}$ & $6 \angle 270^{\circ}$ & $3 \angle 0^{\circ}$ \\
\hline
\end{tabular}




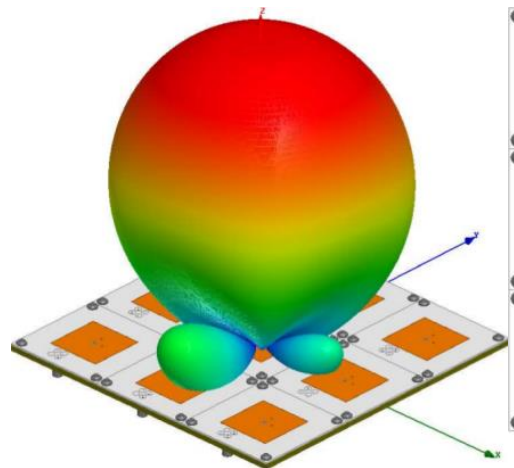

(a)

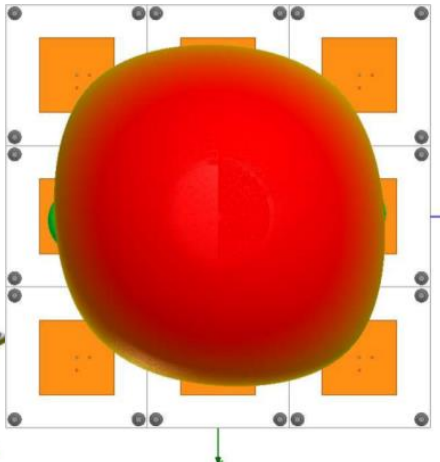

(b)

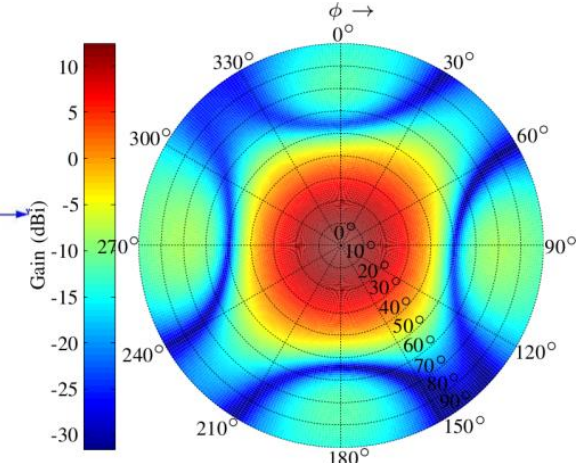

(c)

Fig.14. Simulated radiation pattern (RHCP) obtained with the excitation coefficients listed in Table V: (a) Isometric view; (b) Top view; (c) polar plot.

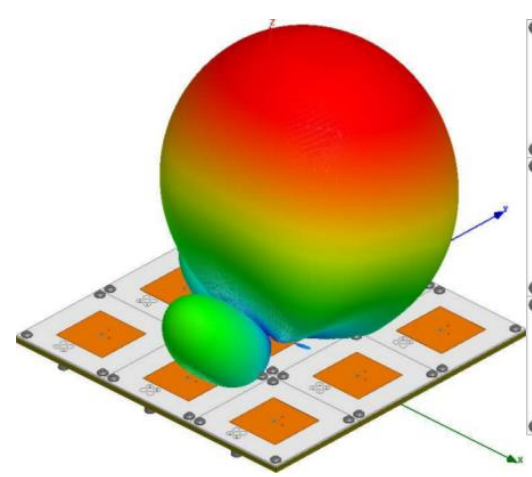

(a)

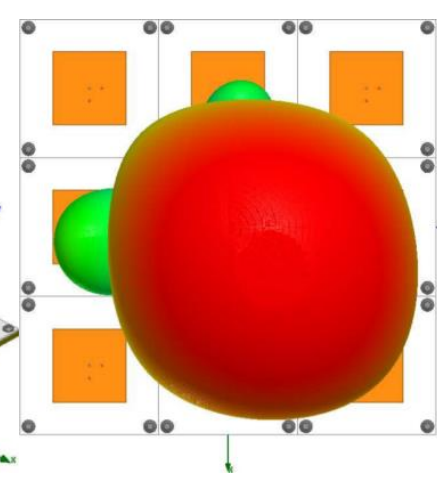

(b)

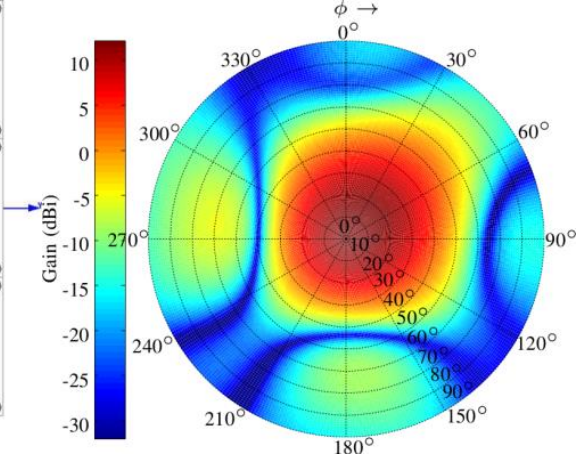

(c)

Fig.15. Simulated radiation pattern (RHCP) obtained with the excitation coefficients listed in Table VI: (a) Isometric view; (b) Top view; (c) polar plot.

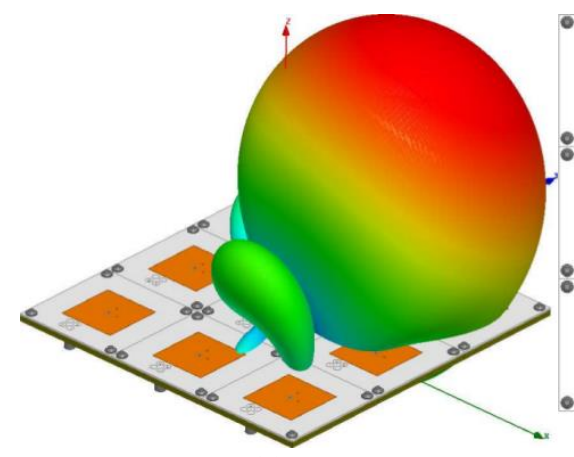

(a)

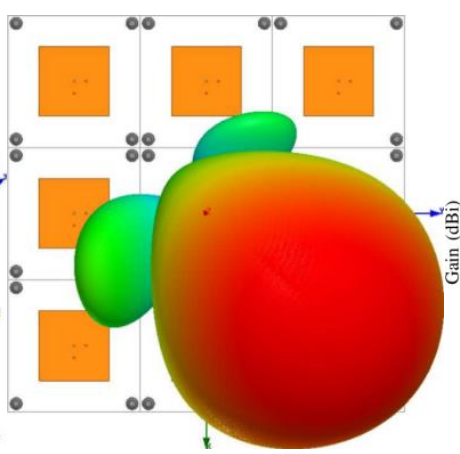

(b)

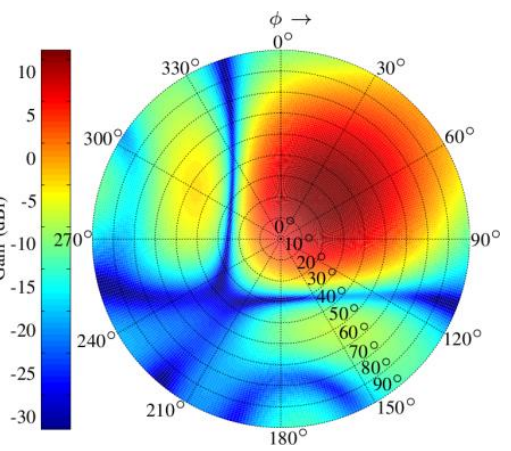

(c)

Fig.16. Simulated radiation pattern (RHCP) obtained with the excitation coefficients listed in Table VII: (a) Isometric view; (b) Top view; (c) polar plot.

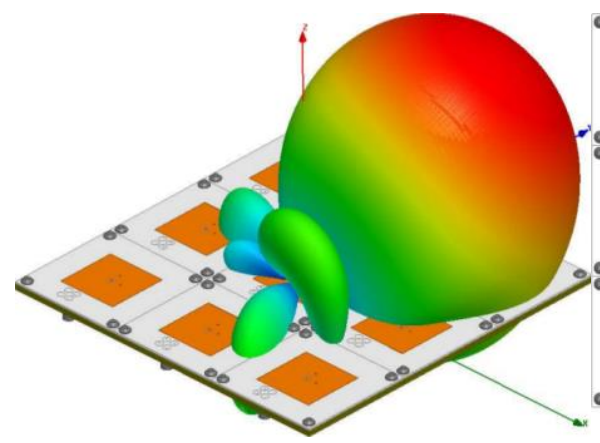

(a)

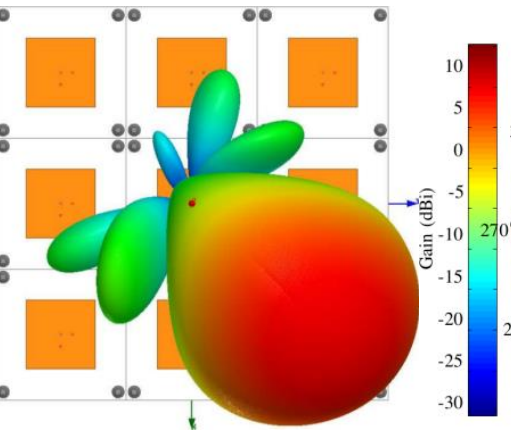

(b)

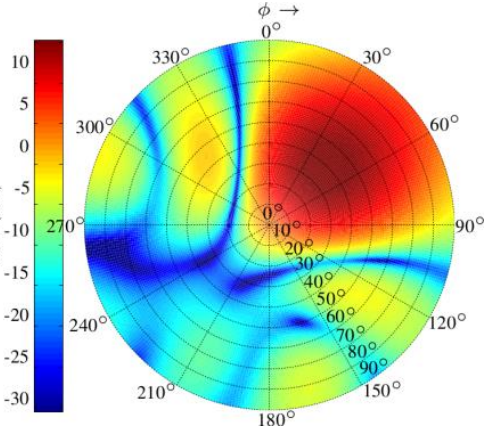

(c)

Fig.17. Simulated radiation pattern (RHCP) obtained with the excitation coefficients listed in Table VIII: (a) Isometricview; (b) Top view; (c) polar plot. 
TABLE IX. COMPARISON BETWEEN THE ACHIEVED GAINS AND SIDELOBE LEVELS.

\begin{tabular}{cccccccccc}
\hline \multicolumn{2}{c}{$\begin{array}{c}\text { Desired } \\
\text { direction }\end{array}$} & \multicolumn{2}{c}{$\begin{array}{c}\text { Gain in the desired } \\
\text { direction (dB) }\end{array}$} & \multicolumn{2}{c}{$\begin{array}{c}\text { Maximum } \\
\text { gain direction }\end{array}$} & $\begin{array}{c}\text { Maximum } \\
\text { gain (dB) }\end{array}$ & SLL (dB) & \multicolumn{2}{c}{ Degradation (dB) } \\
$\theta$ & $\phi$ & & & & $\phi$ & & & Gain & SLL \\
\hline $0^{\circ}$ & $0^{\circ}$ & 12.4 & $0^{\circ}$ & $0^{\circ}$ & 12.4 & -21.1 & 0 & - \\
$15^{\circ}$ & $45^{\circ}$ & 12.0 & $9^{\circ}$ & $47^{\circ}$ & 12.2 & -18.2 & 0.3 & 1.8 \\
$30^{\circ}$ & $45^{\circ}$ & 11.4 & $28^{\circ}$ & $45^{\circ}$ & 11.4 & -16.7 & 0.0 & 3.3 \\
$45^{\circ}$ & $45^{\circ}$ & 10.6 & $38^{\circ}$ & $46^{\circ}$ & 10.9 & -15.8 & 0.3 & 4.2 \\
\hline
\end{tabular}

The failure to comply with the direction of maximum gain and the constraint SLL $\leq-20 \mathrm{~dB}$ can be explained due to the discretization of the excitation coefficients. Better performance seems to be only possible if the number of array elements or the number of bits for representation of the excitation coefficients is increased. However, this is not feasible for the proposed application due to size, weight and system complexity restrictions of the nanosatellite under consideration.

To assess how the beam steering affects the reflection coefficients of the array elements, Fig. 18 shows the variation of the reflection coefficients $\Gamma_{(m, n)}$ for the four patterns shown above. The elements $(1,1),(2,1)$ and $(2,2)$ stand for antennas located on the corner, edge and on the middle of the array, respectively. Based on the plotted curves, the beamsteering seems to have little impact on the reflection coefficients.

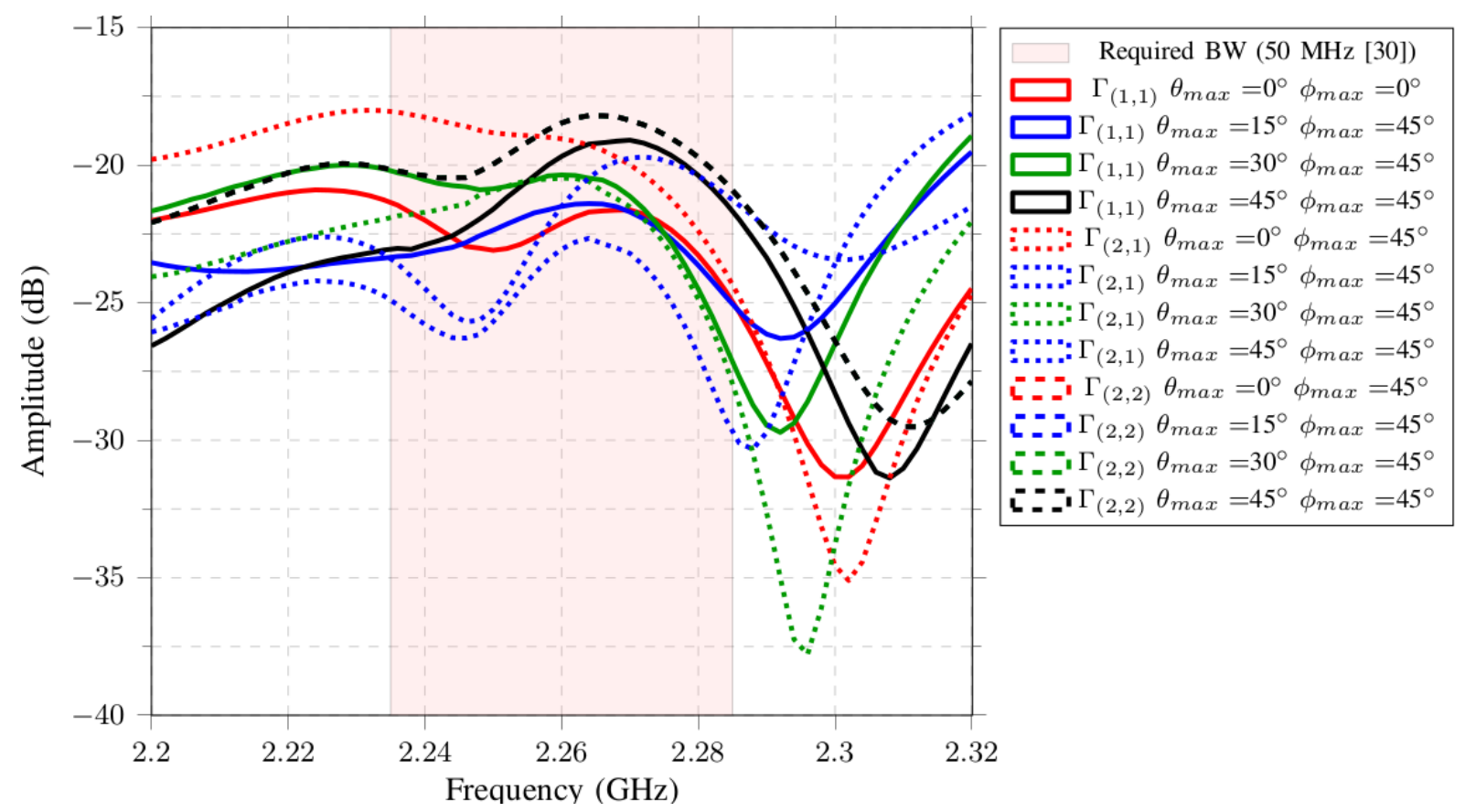

Fig.18. Reflection coefficients for different beam steering directions.

\section{CONCLUSION}

In this paper, the use of an optimization code based on the Firefly Algorithm (FA) was demonstrated for the synthesis of a non-uniformly spaced linear antenna array, a non-uniformly spaced planar array and for a uniformly spaced planar microstrip array. Initially, the mathematical 
background needed to understand and implement the FA was presented. As main results, the synthesized radiation patterns exhibited good agreement with the desired masks for the three cases considered. The main contribution of this paper is to demonstrate the efficiency of the FA for the optimization of complex radiation patterns, which have been synthesized for a variety of array geometries.

\section{ACKNOWLEDGMENT}

This study was financed partially by Coordenação de Aperfeiçoamento de Pessoal de Nível Superior (CAPES) - Finance Code 001.

\section{REFERENCES}

[1] C. A. Balanis, Antenna Theory: Analysis and Design. $3^{\text {rd }}$ Ed., John Wiley\& Sons, 2005.

[2] J. Holland, Adaptation in Natural and Artificial Systems. $2^{\text {nd }}$ Ed., University of Michigan Press, 1992.

[3] R. L. Haupt, “Thinned arrays using genetic algorithms," IEEE Transactions on Antennas and Propagation, vol. 42, no. 7, pp. 993-999, 1994.

[4] J. M. Johnson and Y. Rahmat-Samii, "Genetic algorithms and method of moments (GA/MoM) for the design of integrated antennas," IEEE Transactions on Antennas and Propagation, vol. 47, no. 10, pp. 1606-1614, 1999.

[5] K. Chen, X. Yun, Z. He, and C. Han, "Synthesis of sparse planar arrays using modified real genetic algorithm," IEEE Transactions on Antennas and Propagation, vol. 55, no. 4, pp. 1067-1073, 2007.

[6] X. Ding, B.-Z. Wang, G. Z., and X.-M. Li, "Design and realization of a GA-optimized VHF/UHF antenna with "onbody" matching network," IEEE Antennas and Wireless Propagation Letters, vol. 9, pp. 303-306, 2010.

[7] E. R. Schlosser, R. L. Farias, M. V. T. Heckler, and R. Machado, "Optimization of switched-beam arrays for communication systems," $11^{\text {th }}$ International Symposium on Wireless Communications Systems, Barcelona, Spain, Aug. 2014.

[8] J. Robinson and Y. Rahmat-Samii, "Particle swarm optimization," IEEE Transactions on Antennas and Propagation, vol. 52, no. 2, pp. 397-407, 2004.

[9] J. Kennedy and R.Eberhart, "Particle swarm optimization in electromagnetics," International Conference on Neural Networks, Perth, Australia, pp. 1942-1948, Nov. 1995.

[10] M. M. S. Taheri, A. R. Mallahzadeh, and A. Foudazi, "Shaped beam synthesis for shaped reflector antenna using PSO algorithm," 6 th European Conference on Antennas and Propagation, Prague, Czech Republic, Mar. 2012.

[11] S. M. Tolfo. Desenvolvimento de uma ferramenta computacional para sintese de redes de antenas. BSc. thesis, Universidade Federal do Pampa, 2016.

[12] D. L. Lemes, R. L. Farias, L. A. Greda, and M. V. T. Heckler, “Analysis of dual-band non-uniformly spaced arrays for mobile communications,"2017International Microwave and Optoelectronics Conference, Águas de Lindoia, Brazil, Aug. 2017.

[13] M. Dorigo, Optimization, Learning and Natural Algorithms. PhD thesis, Politecnicodi Milano, 1992.

[14] O.Quevedo-Teruel and E. Rajo-Iglesias, "Ant colony optimization in thinned array synthesis with minimum sidelobe level,"IEEE Antennas and Wireless Propagation Letters, vol. 5, pp. 349-352, 2006.

[15] S.Mosca and M. Ciattaglia, "Ant colony optimization to design thinned arrays," 2006IEEE Antennas and Propagation Society International Symposium, Albuquerque, NM, Jul. 2006.

[16] S. Mosca and M. Ciattaglia, "Ant colony optimization applied to array thinning," 2008 IEEE Radar Conference, Rome, Italy, May 2008.

[17] E. R. Schlosser, C. D. Johann, andM. V. T. Heckler, "Síntese de redes de antenas isotrópicas aplicando o método de colônia de formigas," MOMAG 2016, Porto Alegre, Brazil, Jul 2016.

[18] L. Pappula and D. Ghosh, "Linear antenna array synthesis using cat swarm optimization," International Journal of Electronics and Communications, vol. 68, pp. 540-549, 2014.

[19] K.Slavakis and I. Yamada,"Robust wideband beamforming by the hybrid steepest descent method,'IEEETransactions on signal preocessing, vol. 55, no. 9, pp. 4511-4522, Sep 2007.

[20] S.Koziel and S. Ogurtsov, "Linear antenna array synthesis using gradient-based optimization with analytical derivatives," Antennas and Propagation Society International Symposium, Chicago, IL, Jul 2012.

[21] M. Ibarra, A. G. Andrade, M. A. Panduro, and A. L. Mendez," Design of antenna arrays for isoflux radiation in satellite systems," $33^{\text {rd }}$ International Performance Computing and Communications Conference, Austin, TX, Dec. 2014.

[22] A.Zamuda, J. Brest, B. Boskovic, and V. Zumer, "Differential evolution for multiobjective optimization with seladaptation," 2007IEEE Congress on Evolutionary Computation, Singapore, pp. 3617-3624, Sep. 2007.

[23] J. E. Diener, R. D. Jones, and A. Z. Elsherbeni, "Isoflux Phased Array Design for Cubesats," 2017 IEEE International Symposium on Antennas and Propagation, San Diego, CA, pp. 1811-1812, Jul. 2017.

[24] O. Watanabe and T. Zeugmann, SAGA: International Symposium on Stochastic Algorithms. Springer, 2009.

[25] M. A. Zaman and M. A. Matin, "Nonuniformly spaced linear antenna array design using firefly algorithm," International Journal of Microwave Science and Technology, vol. 8, Jan 2012. 
[26] A. Chatterjee, G. K. Mahanti, and A. Chatterjee. "Design of a fully digital controlled reconfigurable switched beam concentric ring array antenna using firefly and particle swarm optimization algorithm," Progress In Electromagnetics Research B, 36:113-131, 2012.

[27] A. Chatterjee, G. K. Mahanti, and G. Ghatak, "Synthesis of satellite footprint patterns from rectangular planar array antenna by using swarm-based optimization algorithms," International Journal of Satellite Communications and Networking, vol. 32, pp. 25-47, Sep 2014.

[28] V. Gopi Ram, D. Mandal, R. Kar, and S. P. Ghoshal, "Design of non-uniform circular antenna arrays using firefly algorithm for side lobe level reduction," International Journal of Computer and Information Engineering, vol. 8, pp. 36-41, 2014.

[29] B. Basu and G. K. Mahanti, "Fire Fly and Artificial Bees Colony Algorithm for Synthesis of Scanned and Broadside Linear Array Antenna," Progress in Electromagnetics Research B, vol. 32, pp. 169-190, 2011.

[30] INPE. Documento de Descrição da Missão (DDM). Centro Regional do Nordeste. Project report, Instituto Nacional de Pesquisas Espaciais (CRN/INPE), 2011.

[31] F. G. Ferreira. Projeto e construção de uma rede de antenas em banda S para nanossatélites. BSc. thesis, Universidade Federal do Pampa, 2016. 